\title{
às vezes julgo-me na iminência de ver o horror: pensar a Europa em os 3 farros. descida aos infermos. de António Aragão e Alberto Pimenta
}

\author{
Inês Cardoso \\ Universidade do Porto - Instituto de Literatura Comparada
}

Resumo: Este ensaio propõe-se a refletir sobre o questionamento das ideias de Europa na correspondência presente em os 3 farros. descida aos infermos. (1984), de António Aragão e Alberto Pimenta. Dotadas de um humor cáustico, estas cartas redigidas entre 1982 e 1983 espelham não apenas uma visão desencantada da sociedade portuguesa da época, como descortinam a ansiedade provocada pela intervenção do FMI e por uma possível adesão do país à CEE. Assim, de pendor reflexivo e ensaístico, este projeto coletivo apresenta-se como uma crítica irreverente que, ao espelhar um país pautado pela incerteza, antecipa preocupações futuras e, na realidade, inquietantemente atuais.

Palavras-chave: António Aragão; Alberto Pimenta; correspondência; Europa

Abstract: This essay aims to reflect on the questioning of the ideas of Europe in the correspondences present in os 3 farros. descida aos infermos. (1984), by António Aragão and Alberto Pimenta. Provided with a caustic humor, these letters written between 1982 and 1983 express not only a disenchanted vision of the Portuguese society at the time, but also reveal the anxiety caused by the intervention of the IMF and the possibile admition of the country to the EEC. Thus, of reflective and essayistic character, this collective project presents itself as an irreverent criticism that, when mirroring a country marked by uncertainty, anticipates future and worryingly current concerns.

Keywords: António Aragão; Alberto Pimenta; correspondence; Europe 
No Rossio encontrei a súbita aparição dum antigo colega de escola. Parecia embrulhado num futuro disforme e compacto. Vinha convicto. Exaltado. Quase não o reconhecia. Depois dumas trocas de palavras contra tudo ele enfiou-me a ideia de comprar sapatos e camisas em saldos. Que era em conta. Que depois não se sabia onde os preços iriam parar, que sapatos cá eram melhores que lá, que depois da CEE já não sei o quê, que a Europa não era a América, que o subdesenvolvimento era isso mesmo, que a inflação não passava da inflação, que o desarmamento podia dar armamento, etc., etc. Merda. (Aragão/Pimenta 1984: 7)

Assim escreveu António Aragão numa carta enviada a Alberto Pimenta, inaugurando a troca de currespondências que viria a compor os 3 farros. descida aos infermos., publicado em 1984. 0 recurso ao tom iminentemente crítico a que ambos os poetas desde sempre nos habituaram permite-nos já adivinhar o pendor cáustico que caracteriza este longo diálogo. Talvez por isso se torne válido questionar: a quem se dirigem, na verdade, estas cartas redigidas entre fevereiro de 1982 e dezembro de 1983? O reconhecimento do ímpeto criativo que invadiu o Portugal desta década, bem como o entendimento da constante necessidade de experimentação que talha o percurso dos poetas em causa, anula, a priori, a possibilidade de nos encontrarmos perante uma mera troca de correspondência entre amigos. Sendo verdade que o ato de escrita se afigura como um instrumento capaz de diluir essa "aflitiva distância marítima" (idem: 18), o certo é que se torna evidente que a mensagem patente nesta obra prevê o seu verdadeiro destinatário em cada potencial leitor. Na realidade, a própria adoção e consequente desconstrução do modelo epistolar confirma a intenção dos poetas em alear o pendor ensaístico deste projeto a um exercício lúdico que, sistematicamente, visa valorizar as potencialidades criativas da linguagem.

Perante um país que descreditava já a utopia prevista após a Revolução de 74, Pimenta e Aragão dão conta de um contexto social no qual a instabilidade e o desalento se reificam. Servindo-se de uma textualidade profundamente criativa, cuja originalidade resvala na criação de inúmeros neologismos, na utilização sincopada de palavras, no emprego de novas regras de translineação e até no excessivo uso de marcadores visuais (Coelho 2015: 55), os poetas procuraram testemunhar um Portugal fragmentado pela intervenção do FMI e por uma possível adesão à CEE. Assim, os episódios relatados nesta 
obra coletiva não apenas permitem o entendimento de uma sociedade na qual as opiniões parecem polarizar-se, como validam o acesso à visão disfórica dos dois autores. Importa recordar que se por um lado António Aragão é unanimemente considerado como um dos mais ativos nomes da Poesia Experimental Portuguesa, por outro Alberto Pimenta desde sempre recusara qualquer tipo de vínculo ao movimento. Porém, estas considerações não invalidam a existência de uma evidente partilha de preocupações estéticas aquando de contextos históricos conturbados: primeiramente, a Ditadura do Estado Novo; em seguida, o período de emergência e consequente sedimentação das políticas neoliberais.

Em A Agonia de Eros, Byung-Chul Han afirma que a "sociedade do rendimento está dominada na sua totalidade pelo verbo poder, por oposição à sociedade da disciplina, que formula proibições e utiliza o verbo dever" (Han 2014: 17). Neste sentido, revela-se interessante constatar que pensar a Europa no período em que estas cartas foram produzidas implica, simultaneamente, a revisitação de um país talhado por um pensamento ainda em transformação. Destaque-se, por exemplo, a existência de uma forte memória coletiva em torno da Guerra Colonial: "Insistiu na urgência de haver mortos para salvar a pátria e que também me ia apresenta garotas boas" (Aragão/Pimenta 1984: 9). Os resquícios do conservadorismo político e religioso são também facilmente detetáveis nos vários episódios em que António Aragão partilha histórias sobre a sua tia: “a desgraça vem dos comunistas e o castigo vem de Nosso Senhor. (...) 0 aumento dos preços vem dos comunistas e a doença dela no fígado foi mandada por Nosso Senhor. Então conforma-se com Nosso Senhor e não tolera os comunistas" (idem: 93).

Todavia, importa relevar que, tal como refere Rosa Maria Martelo, "o neoliberalismo diz-nos (e repete-nos) que vivemos sempre entre o risco e a competitividade, num mundo onde apenas triunfam os que são guiados por objetivos como os de optimizar a produtividade, a qualidade, a eficiência" (Martelo 2013: 6). Ora, ao reconhecermos a capacidade transformadora do discurso, compreendemos que será também a este nível que se legitimam os jogos de poder. Não deixa de ser curioso, por isso, constatar que uma certa subjugação da humanidade a este tipo de lógicas discursivas parecia encontrar-se já inculcada na própria atividade dos media: 
O sujeito afirmava que havia muito trabalho a fazer. Que a paz sem trabalho nunca se conseguia. Que o trabalho era a autêntica revolução. Que o trabalho, fosse qual fosse, era necessário para o país, para o bem de todos (do corpo de toda a nação) como a religião para a alma, para todas as almas, para a alma de todo o país. (Aragão/Pimenta 1984: 32)

Efetivamente, os poetas denunciam uma sociedade na qual a multiplicação de vo zes opinativas não contribui para a existência de reflexões consistentes em torno da atualidade, mas sim para a progressiva sedimentação de uma visão acrítica do mundo. Nas palavras de Leonor Martins Coelho, a "imagem que os autores dão desse país chamado Portugal, nos primeiros anos da década de oitenta, não favorece os portugueses, em geral, nem os seus governantes, em particular" (Coelho 2015: 56). Perante uma correspondência que condena veementemente qualquer abuso de poder, não nos surpreenderá que o a taque ao espectro político-económico caminhe, não raras vezes, acompanhado de uma crítica mordaz dirigida ao afunilamento perpetrado pelos meios de comunicação:

Já devias ter ouvido falar nisso. Sensibilização do putrimónio. Pinturas. Esculturas. Putedo. Castelos. Desvios de dinheiro. Igrejas. Tudo. Sensibilização de tudo. Putrimónio de tudo. Ia até lembrar que já devias ter visto algum programa sobre isso na Televisão, mas recordo que só tens visão em casa. Mas se os gajos descobrem que usas visão sem tele ainda te obrigam a pagar taxa especial. (Aragão/Pimenta 1984: 27)

Acresce mencionar que um ímpeto de falsa participação coletiva parece assolar este país movido pela incerteza. Aragão afirma, aliás, ao recordar uma greve geral: “A verdade é que me apeteceu misturar com eles e desalmar contra o governo. (...) Mas a ideia de repetir o que os outros faziam confundiu-me. Então acabei por permanecer quieto, afundado numa espécie de diarreia social que de certo modo me anulava" (idem: 7). Este profundo desencanto face à presente realidade portuguesa estende-se, na verdade, ao futuro que o país pretende traçar. De facto, o pendor tragicómico que caracteriza estas correspondências leva-nos a compreender que os autores se sentem também prisioneiros de uma nação sem rumo. Podendo a adesão à CEE ser vista por alguns como uma possível salvação, o certo é que não o é para todos: 
a cee faz-me alergia. às vezes, quando calha de ouvir piar cee nos seus vários idiomas, sinto arrepios no couro cabeludo e é como se tivesse uma comichão chata pela espinha abaixo até ao cu. instinto regressivo, diria o moura mendes (primo do reis mendes): vontade de querer mexer com o rabo, abanar a ponta como um gato quando vê o cão. a cee faz-me alergia. as normas da cee, os quadros da cee, o «parque automóveis» da cee, a higiene an(u)al da cee, a comida para cães da cee, os investimentos da cee, os investimentos e as investidas e os vestidos e as vestimentas da cee, faz-me alergia até ao cu, pronto. mais do que a cee talvez só as nações unidas, a fazer a guerra dos outros para obter a sua paz em dólares. (idem: 104)

Como seria expectável, a crítica produzida em torno das instituições europeias e mundiais não admite complacências. Embora os autores espelhem preocupações que assombram o quotidiano comum do povo português, torna-se difícil não constatar a existência de uma profunda lucidez na análise que ambos fazem da conjuntura internacional. Não raras são as vezes em que podemos encontrar referências a ameaças à paz mundial, de tal modo que não só o cenário da Guerra Fria é frequentemente mencionado, mas também a Guerra das Malvinas e o conflito no Líbano. De resto, a descrença de Pimenta face aos benefícios das relações diplomáticas impostas pelas instituições internacionais não surge isoladamente nesta troca de correspondências. Vários são os momentos na sua obra em que nos confrontamos com uma denúncia que ataca desenfreadamente estes organismos, referindo-os enquanto promotores de estratagemas que acentuam as discrepâncias entre países. Também Aragão, com profunda ironia, desacreditava já nas vantagens de um novo mapa geopolítico: "Como vês roubam-te também as palavras e tu a falares-me da nova escrita! Não será que o país tem outra escrituração? Talvez por causa da desintegração na CÊEIÊ. Ou em virtude da falta de mísseis ou de missas?" (idem: 49).

Num país em que a cultura é permanentemente descurada, a possível adesão à CEE parece acarretar, igualmente, o reforço de certas preocupações. Os poetas utilizavam já um discurso manifestamente disfórico para descrever uma sociedade obcecada por tudo aquilo que é fabricado e na qual o ato de consumo surge enquanto sinónimo de felicidade. A cultura - que segundo António Aragão "tem a soberana vantagem de começar por cu" 
(idem: 111) -, apresenta-se absorvida pelas distribuidoras, pelos partidos políticos e até pelas grandes construtoras, sendo difícil não relembrar o conceito de indústria cultural, proposto por Adorno e Horkheimer, na obra Dialetic of Enlightenment ${ }^{1}$. De facto, a obra de arte não encontra um espaço seguro neste Portugal movido pela ânsia de alcançar uma economia competitiva, ancorada pelos novos laços previstos na CEE:

enquanto isto, entretenho-me com prospectos falando da «sublime trilogia» ou apresentando um novo supergrelhador com resistência tubolar segundo as normas da cee e ultra-rápido, económico, sem fumos, sem cheiros, antiaderente, polivalente, resistente, distensível... até parece a nova escrita das traseiras: as fadas do lar (sempre melhor que as fodas do ler), os cachorros a ladrar... (idem: 44)

No ano de 2006, Alberto Pimenta foi entrevistado por Rui Ramos para um programa intitulado $O$ Portugal de..., com emissão no canal RTP. Quando questionado acerca do que distingue o seu país, o poeta refere que Portugal é igualzinho aos outros (Pimenta 2006: 4.17), ciente de que esta afirmação ofenderia quer aqueles que acreditam que Portugal é melhor do que os outros países, quer aqueles que pensam ser pior. Evidentemente, a utilização da forma diminutiva da palavra igual em nada se revela gratuita, podendo aplicar-se de um modo exímio ao Portugal de os 3 farros. descida aos infermos. Atentemos numa passagem retirada de uma carta redigida pelo autor:

um fulano que vinha no mesmo banco que eu e coçava os colhões todo o tempo percebeu a minha intenção e disse: «pois é, isso ou é reprivatizado ou então não endireita». «o sr. por exemplo já alguma vez encontrou papel higiénico em retretes públicas?», perguntou ele. e acrescentou: «e querem entrar para a cee com estas infra-estruturas!» eu ri-me. «não se ria, isto não é para rir, disse ele, coçando os colhões. e pintava um futuro sombrio: a coisa ia piorar se o governo não tivesse a coragem de reprivatizar pelo menos as retretes da cp. (Aragão/Pimenta 1984: 13)

A conversa prossegue, sendo notória a acentuação do caráter trivial das observações proferidas. 0 recurso à típica expressão "tristeza de país", com que este desconhecido finda o diálogo, revela-se sintomático de dois pontos essenciais: em primeiro lugar, de que se trata de uma sociedade ainda vergada pelo espírito subserviente que perdurou ao longo de 
41 anos de ditadura; em segundo, de que a adesão a grupos fortes parece emergir enquanto possibilidade de restituir uma certa confiança perdida. Por outras palavras, o retrato do país pequeno contrasta com a imagem de força transmitida pela tão almejada CEE, originando sentimentos paradoxais. Se por um lado a possível adesão transporta consigo a promessa de um futuro radioso, por outro esta não deixa de se apresentar também como um objetivo inalcançável aos olhos do cidadão diminuído e conformado.

Assim, a coloquialidade profundamente cáustica que caracteriza esta troca de correspondências, alicerça um jogo que, podendo ser entendido como um ataque, inegavelmente constitui também um mecanismo de defesa. Resistir à realidade de um país em estado de decadência implica, para ambos os autores, resistir igualmente a um futuro que se afigura distópico. Note-se que, no início da obra, Aragão nega a possibilidade de que o pavor que sente possa ser causado pelo estado catastrófico em que o país se encontra. Contudo, não deixa de ser verdade que esta "iminência de ver o horror" parece redesenhar se, levando o poeta a afirmar, numa das últimas cartas endereçadas a Alberto Pimenta:

Ia-te escrever não sei quê a propósito não sei de quê. Primeiro que tudo tratava-se duma vontade desmedida de dizer que não está certo, que não pode ser, que assim um gajo não está para isto, que nem vale a pena apostar no totobola, que das duas uma: nu culearização ou desnuculearização, que a alegria da minha vizinha da frente agora me irrita ou incomoda, que o marido dela certamente é corno e se não é devia ser, que o parlamamento ou o cuverno podiam antes organizar bailes de más caras para o povo, que o bispo morreu e já veio outro, que me estou marimbando para os mísseis russos e dos amaricanos, que se tivesse uma bomba atómica à mão cagava-lhe dentro, (...) que até parece não estar certo os aviões não continuarem a passar por aqui por cima para as Malvinas, que a guerra no Líbano ou o papa na televisão já chateiam, que as superpotências e as que não têm potência nenhuma fossem todas berda merda[.] (idem: 111)

Existe, efetivamente, um temor tangível nestas correspondências, resultante de uma constatação possível: a de que nos encontramos num mundo onde a desumanização se constitui como uma ameaça latente. 0 desamparo causado por um quotidiano cada vez mais veloz, no qual os laços, a identidade e a memória parecem não ser priorizados, revela-se transversal aos vários textos que compõem este trabalho coletivo. A questão parece então 
impor-se: podemos falar de um receio face à Europa? Receio, talvez, das ideias que a constroem e, acima de tudo, de um caminho que parece traçar-se no sentido das palavras que Chris Lorenz utiliza no ensaio "If you're so smart, why are you under surveillance? Universities, Neoliberalism, and New Public Management”, publicado em 2012:

Neoliberalism simultaneously shifts its focus from rights to risks; it represents "risk society," job insecurity, and "flexibility" to be the normal, present-day "global" condition. Neoliberalism thus silently uncouples the globalized individual from fundamental rights formerly connected to national citizenship, like the right to schooling and welfare. It trades all these civil rights for one new right: the right to buy services on the privatized service market.

De pendor reflexivo e ensaístico, este projeto conjunto apresenta-se como uma crítica irreverente que, ao refletir sobre o Portugal dos anos 80, antecipa preocupações futuras e inquietantemente atuais. Com efeito, torna-se desconcertante verificar que, se nos propusermos a considerar os contributos de vários poetas contemporâneos, as batalhas de hoje parecem não diferir muito daquelas que Pimenta e Aragão travaram no período em que estas cartas foram redigidas. Porém, resistir é também persistir no caminho, pois como refere José Miguel Silva:

um poeta não pode deixar de declarar guerra a todo o género de clichés: verbais, desde logo, mas também políticos, filosóficos, psicológicos, etc. Mas sem nunca perder de vista que, numa era de comunicação de massas, essa sua guerra é tão desigual, e portanto tão caricata, como a guerra que uma sardinha (zangada) decidisse mover a um petroleiro (de aço). (Silva 2012: s.p.)

N. 38 - 6/ 2018 | 429-438 - ISSN 2183-2242 | http:/dx.doi.org/10.21747/21832242/litcomp38v7 


\section{NOTAS}

1 Recuperar o conceito de indústria cultural torna-se, neste contexto, particularmente pertinente. Note-se que a análise proposta por Horkheimer e Adorno procura demonstrar o modo como, em pleno contexto político do capitalismo, a arte se confronta, cada vez mais, com o perigo de submergir na ideologia de mercado, configurando-se como um produto de consumo. Trata-se, no fundo, de fazer com que a obra de arte obedeça aos desejos do público, neutralizando qualquer ato de resistência e oprimindo a própria a liberdade de criação. Nas palavras dos dois pensadores:

The standardized forms, it is claimed, were originally derived from the needs of the consumers: that is why they are accepted with so little resistance. In reality, a cycle of manipulation and retroactive need is unifying the system ever more tightly. What is not mentioned is that the basis on which technology is gaining power over society is the power of those whose economic position in society is strongest. Technical rationality is the rationality of domination. It is the compulsive character of a society alienated from itself. (Adorno/Horkheimer 2012: 95)

2 Este artigo foi desenvolvido no âmbito do Programa Estratégico UID/ELT/00500/2013 - P0CI-01-0145FEDER-007339 e decorre de uma comunicação apresentada à Faculdade de Letras da Universidade de Lisboa, no âmbito do I Encontro de Jovens Investigadores em Literatura Comparada.

\section{Bibliografia}

Aragão, António / Alberto Pimenta (1984), os 3 farros. descida aos infermos, Lisboa, Danúbio.

Coelho, Leonor Martins (2015), “'os 3 farros. descida aos infermos. currespondências' de Alberto Pimenta e de António Aragão: textualidades criativas sobre um País e um Mundo à 
deriva", Cibertextualidades, nํㅜ 7, 53-60.

Han, Byung-Chul (2014), A Agonia de Eros, tradução de Miguel Serras Pereira, Lisboa, Relógio D’Água Editores.

Adorno, Theodor / Max Horkheimer (2002), Dialectic of Enlightenment: Philosophical Fragments [trad. Edmund Jephcott], California, Stanford University Press.

Lorenz, Chris (2012), "If you're so smart, why are you under surveillance? Universities, Neoliberalism, and New Public Management", Critical Inquiry, vol. 38, no 3, 599-629.

Martelo, Rosa Maria (2013), “Questões de Vocabulário”, Cão Celeste, no 4, 5-13.

Pimenta, Alberto (2006), "Portugal de... Alberto Pimenta", documentário realizado pela RTP com Alberto Pimenta e Rui Ramos, <www.rtp.pt/arquivo/index.php?article=3685\&tm =52\&visual=4> (último acesso em 10 de setembro de 2016).

Silva, José Miguel (2012), "Resposta ao Inquérito de LyraCompoetics", <http://ilcml.com/blog/inquerito-poesia-e-resistencia-portugal/>.

Inês Cardoso é doutoranda em Estudos Literários, Culturais e Interartísticos na Faculdade de Letras da Universidade do Porto. Concluiu, na mesma instituição, o mestrado em Estudos Literários, Culturais e Interartes, com uma dissertação intitulada O futuro já mostra que ontem foi há muito tempo: A resistência à globalização em Alberto Pimenta. Integra o Instituto de Literatura Comparada Margarida Losa como investigadora. 